collective one-in the region of large deformation are much higher in energy than one would predict from the Nilsson model, in which the particles are assumed to move independently in a distorted well. This can be explained by a correlation between pairs of particles of opposite magnetic quantum number, in an unfilled shell. This pairing in angular momentum is similar to the pairing in linear momentum in the Bardeen, Cooper and Schrieffer model. Bayman discussed calculations of Beliaev, who incorporated the pairing simply by making a transformation to a quasi-particle representation. In the region near closed shells, the pairing correlation leads to so-called vibrational states. Their energy spectrum is essentially that produced by Racah's pairing force, so that many of the results of the seniority scheme can be used. In the discussion J. P. Elliott (Southampton) reported on the status of his generalized shellmodel approach, and Prof. Peierls discussed briefly the variational scheme for obtaining rotational levels.

The conference was considered by all present to have been a great success, and $I$ for one hope that another conference on the same subject can be arranged in a few years time to review the progress made in the intervening period. D. TER HAAR

\title{
INDUSTRIAL HEALTH IN BRITAIN
}

$\mathrm{T}$ HE annual report of the Chief Inspector of Factories on Industrial Health for the year $1957^{*}$ is the first report on industrial health to be published separately and is, to some extent, experimental. Its first chapter, reviewing the year, deals with general questions, including references to new and developing problems and to progress made in solving old problems. The second chapter deals with cases of industrial disease, poisoning and gassing which occurred during the year, and the third chapter deals more extensively with industrial dermatitis. Points which were raised on the statutory draft Compressed Air Special Regulations were all resolved by the end of the year, and the Regulations came into operation on April 21, 1958. The report of the pilot industrial health survey of Halifax was studied in detail by a sub-committee of the Industrial Health Advisory Committee, and afterwards an abridged version of the report was published and arrangements were made for the survey team to approach occupiers of factories in Halifax employing more than 250 workers with the view of interesting them in the advantages of the provision or extension of medical and nursing services.

A committee of inquiry into precautions against anthrax was set up in February 1957, and there was evidence during the year that factory occupiers pay insufficient attention to making adequate provision for first-aid treatment, as required under the Fac-

* Ministry of Labour and National Service. Annual Report of the Chief Inspector of Factories on Industrial Health for the year 1957. tories Act. In the light of discussions between representatives of Government departments which have responsibilities for first aid, including representatives of the Medical Research Council, the contents of first-aid boxes in factories, as prescribed by the First Aid in Factories Order, 1938, and the leaflet giving advice on first aid treatment have been reviewed, while measures to stimulate recruitment and training of first-aid personnel were also discussed. The third interim report of the Joint Advisory Committee of the Cotton Industry on "Dust in Card Rooms" has been brought to the notice of all firms concerned, and it has been made clear to occupiers that, since a satisfactory system of removing dust in card rooms is now available, it is expected that early action will be taken. Plans were made for extending the Inspectorate's facilities for collecting and analysing dust by formation of a second dustcounting team.

The chapter on industrial dermatitis summarizes known facts on the cause and particularly the prevention of this disease which have already been made known in departmental and other publications. Predisposing factors are also indicated, and stress is laid on the importance of taking appropriate measures before and not after trouble has occurred. These include replacement of the harmful agent by one that is non-irritant or less harmful; selection of personnel ; reduction of contact to a minimum, or complete elimination of contact; regular and frequent inspec. tion by trained observers; and cleansing of the skin.

\section{INTERNATIONAL STANDARDS FOR DRINKING-WATER}

$\mathrm{T}$ THERE is at present a wide diversity in water treatment and quality in different countries, and the need for some sort of international agreement on what constitutes a safe supply of drinking-water has long been apparent. The question was raised at the Congress of the International Water Supply Association in Amsterdam in 1949 and again in Paris in 1952, but the prospect of accord in the near future seemed remote. In 1953 the matter was taken up by the World Health Organization, and a questionnaire was circulated to member States. The replies served to reiterate the differences in attitude, and in view of the increase in international travel, particularly by air, 10 emphasize the desirability of agreed standards.
Regional study groups of experts were convened to study the problem in the European, Eastern Mediterranean, and South-east Asia and Western Pacific regions. The reports of these various groups were used as a basis for discussion by a further group meeting in Geneva in 1956 and the standards now proposed were put forward by this body. It is not suggested that these standards represent perfection ; on the contrary, as the preface specifically points out, they are tentative and subject to modification after experience of their application. In some cases the standard proposed is not as high as that habitually achieved by some undertakings, but the sources of water supply used for public consumption are so 
different in their chemical and bacteriological content and treatment methods so limited by technical and financial resources that it is not to be expected that the high standard reached in certain localities will immediately become universally applicable. The standards suggested represent rather the minimum requirements to which a public water supply should conform and in the absence of which it cannot be considered entirely free from risk. This is in itself a great advance and will be of inestimable value to health and water authorities in those parts of the world where at present water supplies do not attain the desired criteria.

In the International Standards for Drinking Water*, recently published by the World Health Organization, a chapter is devoted to each of the subjects of bacteriological, chemical and physical, biological and radiological requirements. This is followed by a section in which are indicated matters requiring further research in each of these fields. In some cases it might appear that the subject sug. gested for study has already been adequately investigated, but it can do no harm for some old ground to be re-covered if the results are made more widely known and a re-assessment of some cherished beliefs may prove salutary.

In a rapidly expanding subject it is inevitable that a publication of this kind should be somewhat behind the latest information. This applies particularly to the chapter on radiological requirements, which seems unduly brief. There is no mention of the part

* World Health Organization. International Standards for Drinking Water. Pp. 152. (Geneva: World Health Organization; London H.M. Stationery Office, 1958.) 12 Swiss franes; 20 s. ; 4 dollars. played by the naturally occurring isotope, potassium-40, in contributing towards the total radioactivity in water, although it is only fair to say that for further information the reader is referred to the recommendations of the International Commission on Radiological Protection.

Any consideration of standards, particularly in the bacteriological or chemical spheres, must take some account of the methods whereby these are measured, and the second, and larger, portion of the book is devoted to a series of approved methods for bacteriological, chemical and biological examination of water. Starting with a list of required materials, each procedure is explained step by step in simple language which is a model of clarity. Not the least important sections are those detailing the particulars to be supplied with samples and the recommendations on the frequency of sampling. Tables are given for the computation of the most probable number index with upper and lower confidence levels. In the chemical section, lists with permissible levels are provided not only of those naturally occurring substances which may affect potability but also of toxic materials such as lead, arsenic, selenium, chromium and cyanide, with details of methods for their estimation.

If one may venture a further minor criticism of so valuable a work, it is that a comprehensive index might have increased its usefulness. As it is, the volume is an excellent example of what can be achieved by international co-operation and a milestone on the way to safe water supplies throughout the world.
E. WINDLE TAYLOR

\section{THE WEIZMANN INSTITUTE OF SCIENCE}

\begin{abstract}
THE report for 1956-57 of the Weizmann Institute of Science*, besides summarizing the scientific activities of the several departments and sections, includes a list of publications during the period and details of the scientific staff, as well as of the administrative and technical staff and supporting committees. It is introduced by a statement of policy for the future of the Institute by Mr. M. W. Weisgal, chairman of the Executive Council, which expresses grave concern regarding the financial position of the Institute. Anticipated income for the four years April 1956-March 1960 fell short of estimated requirements by about 6 million dollars, and the measures proposed by $\mathrm{Mr}$. Weisgal include launching a campaign for an Endowment Fund of 25 million dollars.

Fundamental research in the Department of Applied Mathematics was directed mainly to the solution of mathematical problems in statistical mechanies, wave propagation, geophysies, hydrodynamics and X-ray crystallography. In nuclear physics, besides investigation on nuclear models, some work on reactor physics was undertaken for the Israel Atomic Energy Commission. The Department of Isotope Research records progress in the production of stable isotopes, the use of stable and radioactive isotopes in studying the mechanism of inorganic and organic reactions and in various

* Weizmann Institute of Science. Report 1956-1957. Pp. 190. (Rehovoth: Weizmann Institute of Science, 1958.)
\end{abstract}

applications of natural and artificial radioactivity. Investigations by the Department of Organic Chem. istry embraced the structure of natural compounds, the chemistry of the sphingolipids, steroid and acetylene chemistry, syntheses in the terpene series, petroleum chemistry and applied spectroscopy.

Besides studies of polyelectrolytes, including their biological aspects, in the Department of Polymer Research, gels, membranes and mechano-chemistry received attention, as well as polynitroethylene, polyvinyl bromide and polyvinylanthracene. The Department of X-ray Crystallography continued to investigate intra- and inter-molecular compression forces on molecular structure and to study the mechanism of solid-state reactions by combined X-ray crystallographic and physico-chemical methods, while work in the Department of Experimental Biology included such diverse fields as the biological mechanism of the induction of tumours, the metabolism of urethane in relation to its tumour-inducing activity, the mechanism of deciduoma formation and its relation to placental implantation of the ovum, immuno-genetics of tumour implantation, radiobiological aspects of tumour immunity, biochemical and endocrinological aspects of sugar metabolism and problems in human genetics and neuropharmacology. The Department of Biophysics continued to be concerned mainly with work on synthetic poly$\alpha$-amino-acids and their use in elucidating chemical and physical properties of proteins and natural 